\title{
Validation of the Filipino Version of the Berlin Questionnaire to Identify Population at Risk for Sleep Apnea Syndrome
}

\author{
Manuel C. Jorge, ${ }^{1}$ Karla Maria P. Nomorosa ${ }^{2,3}$ and Deborah Ignacia A. David-Ona ${ }^{4}$ \\ ${ }^{1}$ Section of Pulmonary Medicine, Department of Medicine, College of Medicine and Philippine General Hospital, University of the Philippines Manila \\ ${ }^{2}$ Department of Medicine, College of Medicine and Philippine General Hospital, University of the Philippines Manila \\ ${ }^{3}$ Section of Gastroenterology and Digestive Endoscopy, Manila Doctors Hospital \\ ${ }^{4}$ Section of Hypertension, Department of Medicine, College of Medicine and Philippine General Hospital, University of the Philippines Manila
}

\begin{abstract}
Objective. To validate the Filipino version of the Berlin questionnaire $(\mathrm{BQ})$ as a tool to screen for risk of obstructive sleep apnea (OSA) in primary care patients.

Background. Most patients with OSA are unrecognized and untreated. The $B Q$ is a tool that has been validated to screen for patients at risk for OSA and has been translated into and used in different languages.

Method. The forward and backward translation method was applied. The Filipino version was administered to 40 individuals able to read and understand both English and Filipino in different communities within the Metro Manila area followed 24 hours later with the English version. A focused group discussion and feedback were done after.
\end{abstract}

Results. The $\mathrm{BQ}$ in Filipino showed good construct validity supported by the Cramer's coefficient ranging from 0.802 to 1 $(p<0.05)$ for each of the questions.

Conclusions. The BQ in Filipino showed high construct validity. It can now be used as a research tool to conduct studies on risk assessment and disease correlation with OSA in the local community. It may likewise be used as a screening tool especially in areas with limited resources in order to identify patients who may need further workup for OSA.

Key Words: Berlin questionnaire, obstructive sleep apnea, Filipino translation, validation \footnotetext{
2009 Vol 14 Supplement 3 p. A146.

Corresponding author: Karla Maria P. Nomorosa, MD

Department of Medicine

Philippine General Hospital

University of the Philippines Manila

Taft Avenue, Ermita, Manila 1000 Philippines

Telephone: +639175364766

Email: karla.nomorosa@gmail.com
}

Presented at the 14th Congress of the Asian Pacific Society of Respirology, November 14-18, 2009, Seoul, Korea. Abstract published in Respirology Nov

\section{Introduction}

Obstructive sleep apnea (OSA) is a disabling condition characterized by repetitive obstruction of the upper airway often resulting in oxygen desaturation and frequent arousals from sleep. ${ }^{1}$ It is a more serious condition than generally recognized as it does not only predispose to medical complications such as hypertension, ${ }^{2,3}$ coronary vascular disease, ${ }^{4}$ congestive heart failure, ${ }^{5}$ cerebrovascular disease, ${ }^{6}$ glucose intolerance ${ }^{7}$ and impotence, ${ }^{8}$ it may be a social hazard as well leading to daytime somnolence and cognitive impairment resulting in low productivity and increased risk for automobile crashes. ${ }^{9-11}$ Its prevalence is approximately $5 \%$ in both Caucasian and Asian populations. ${ }^{12,13}$ Data indicate that the vast majority of patients with OSA are undetected and untreated. It is estimated that only $10 \%$ of the population has been adequately screened for appropriate diagnosis. ${ }^{14}$ The population who may be at risk for the disease, however, is much larger, and an accurate screening tool to recognize these patients is needed.

The Berlin Questionnaire (BQ) was developed during the Conference on Sleep in Primary Care held in April 1996 in Berlin, Germany, involving 120 U.S. and German pulmonary and primary care physicians. Literature were reviewed and factors or behaviors that persistently correlated to the presence of sleep-disordered breathing across all studies were included in the questionnaire. By consensus, the final questionnaire only focused on a limited set of known risk factors for OSA. ${ }^{15}$

The questionnaire consists of ten questions divided into three categories. The first category consists of five questions that deal with snoring. The second category consists of three questions that deal with waketime sleepiness. The third category asks questions on the presence of hypertension and self-reported height and weight for computation of the body mass index. Risk stratification for obstructive OSA is divided into high and low risk categories based on the responses to the questions in the three categories. The questionnaire has been repeatedly validated using a portable sleep monitoring device ${ }^{15}$ and overnight polysomnography..$^{16,17}$

It has been translated to different languages namely Arabic, Indian, Armenian, and Urdu. Although validation 
of the translated version was not done, these translated versions were still used to conduct the different studies utilizing the BQ. A Filipino version of this questionnaire is currently not available.

\section{Method}

The Questionnaire. The forward and backward translation methodology for bilinguals was used in the study. The Berlin Questionnaire in English including some of the changes made by Sharma et al. was translated to Filipino by a language expert (Appendix A). The translated Filipino version was then translated back to English by another language expert (Appendix B).

Validation and Statistical Analysis. The Filipino version of the BQ was self-administered to 40 adult participants from different communities throughout Metro Manila. After 24 hours, the English version was administered to the same participants. Individual discussions were done and feedback will be elicited from the participants. Items unclear to the participants were also asked.

\section{Results}

Population. Forty participants from communities in Makati, Quezon City, Malabon, Pasig, and Paranaque were involved in the study. Majority of the respondents were males (80\%) with a mean age of 39 years old. The respondents reached at least tertiary level of education. Fluency in both written and spoken English and Filipino was self-reported. All were from the middle income earning class.

Data results. A Cramer's coefficient was used to test for construct validity of the Filipino version of the questionnaire. A Cramer's coefficient closer to one indicates higher correlation between the two responses. Table 1 summarizes the Cramer's coefficient for each question.

Table 1. Construct Validity of the Filipino Version of the Berlin Questionnaire (Cramer's coefficient)

\begin{tabular}{cc}
\hline Question Number & Cramer's Coefficient \\
\hline 1 & 0.972 \\
2 & 1 \\
3 & 0.844 \\
4 & 0.951 \\
5 & 1 \\
6 & 0.94 \\
7 & 0.802 \\
8 & 0.893 \\
9 & 0.861 \\
10 & 1 \\
\hline
\end{tabular}

Each item in the questionnaire was discussed with each participant. Each participant was questioned regarding the straightforwardness of each item and the clarity of each statement in both English and Filipino. Each participant was also questioned regarding terms in each item that were possibly difficult to understand. One on one discussion with the respondents revealed no difficulty in answering the questionnaire. All items and terms were clear. No clarifications were needed by the respondents.

\section{Discussion}

The BQ clearly measures the risk for OSA. The initial validation study conducted by Netzer el $\mathrm{al}^{15}$ used the respiratory disturbance index (RDI) as a tool to diagnose OSA. This study showed $86 \%$ sensitivity for the questionnaire to detect an RDI $>5$, which highly correlates with the presence of OSA. Subsequent studies by Chung et $\mathrm{al}^{16}$ and Sharma et $\mathrm{al}^{17}$ used overnight polysomnography, which is the gold standard for the diagnosis. In the study by Chung et al, ${ }^{16}$ the BQ showed a sensitivity of $65 \%$ to $79 \%$ for the different apnea-hypopnea indices. Sharma et $\mathrm{al}^{17}$ used a modified version of the $\mathrm{BQ}$ and subjected each participant to overnight polysomnography. They reported a sensitivity of $86 \%$. These findings help to confirm the validity of the BQ as a measure for the risk of sleep OSA in the general population.

Questionnaires are generally in the native language of the author. This limits its use in a population that neither reads nor writes in that language. It is therefore valuable to have a local translation of that questionnaire in order for it to be used in the population to be studied. Differences in culture and in use of language may cause loss of meaning in the translated work. The $\mathrm{BQ}$ has been translated into different languages and has been shown to be effective in assessing risk for OSA in those languages. The Filipino version, likewise, must show consistency when administered to patients despite the translation.

Construct validity is a test to determine the nearness of the meaning of the two versions of the same question. This is measured by correlating the responses to the individual items in the two versions by using the Cramer's coefficient. A value closer to one shows good construct validity. The pattern of the Cramer's coefficient for each of the questions for both the English and Filipino versions showed a result of 0.802 to 1 . This study, therefore, showed good construct validity of the test.

More practitioners are now becoming aware of the presence of OSA and its possible hazards both medically and socially. Its diagnosis is highly limited by both the expense of diagnostic modalities and the availability of equipment. The validation of the Filipino version of the $\mathrm{BQ}$ can now fill in this gap. It is a handy tool in recognizing high risk groups in need of further testing. Furthermore, it may aid in further research and in improving health care policies.

\section{Conclusion and Recommendations}

The Filipino version of the BQ showed good construct validity in line with the English version. With the availability of this translation, it can now be used as a 
research tool to conduct studies on risk assessment and disease correlation with OSA in the local community. It may likewise be used as a screening tool especially in areas with limited resources in order to identify patients who may need further workup for OSA.

It may also be used as a tool in formulating health care policies in terms of health care compensation for the diagnostic work up and treatment of the condition.

We recommend further testing to validate the Filipino version of the questionnaire by correlating the scores of patients to results of overnight polysomnography, the gold standard for diagnosing OSA. This will further strengthen its use as a screening modality for groups at risk for OSA.

\section{References}

1. Sleep-related breathing disorders in adults: recommendations for syndrome definition and measurement techniques in clinical research. The Report of an American Academy of Sleep Medicine Task Force. Sleep. 1999; 22(5):667-89.

2. Nieto FJ, Young TB, Lind BK, et al. Association of sleep-disordered breathing, sleep apnea, and hypertension in a large community-based study. Sleep Heart Health Study. JAMA. 2000; 283(14):1829-36.

3. Peppard PE, Young T, Palta M, Skatrud J. Prospective study of the association between sleep-disordered breathing and hypertension. $\mathrm{N}$ Engl J Med. 2000; 342(19):1378-84.

4. Peker Y, Hedner J, Norum J, Kraiczi H, Carlson J. Increased incidence of cardiovascular disease in middle-aged men with obstructive sleep apnea: a 7-year follow-up. Am J Respir Crit Care Med. 2002; 166(2):15965.

5. Kaneko Y, Floras JS, Usui K, et al. Cardiovascular effects of continuous positive airway pressure in patients with heart failure and obstructive sleep apnea. N Engl J Med .2003; 348(13):1233-41.

6. Yaggi HK, Concato J, Kernan WN, Lichtman JH, Brass LM, Mohsenin V. Obstructive sleep apnea as a risk factor for stroke and death. N Engl J Med. 2005; 353(19):2034-41.

7. Babu AR, Herdegen J, Fogelfeld L, Shott S, Mazzone T. Type 2 diabetes, glycemic control, and continuous positive airway pressure in obstructive sleep apnea. Arch Intern Med. 2005; 165(4):447-52.

8. Goncalves MA, Guilleminault C, Ramos E, Palha A, Paiva T. Erectile dysfunction, obstructive sleep apnea syndrome and nasal CPAP treatment. Sleep Med. 2005; 6(4):333-9.

9. Engleman HM, Martin SE, Deary IJ, Douglas NJ. Effect of CPAP therapy on daytime function in patients with mild sleep apnoea/hypopnoea syndrome. Thorax. 1997; 52(2):114-9.

10. George CF. Reduction in motor vehicle collisions following treatment of sleep apnoea with nasal CPAP. Thorax. 2001; 56(7):508-12.

11. Turkington PM, Sircar M, Saralaya D, Elliott MW. Time course of changes in driving simulator performance with and without treatment in patients with sleep apnoea hypopnoea syndrome. Thorax. 2004; 59(1):56-9.

12. Davies RJ, Stradling JR. The epidemiology of sleep apnoea. Thorax. 1996; 51 Suppl 2:S65-70.

13. Lam B, Lam DC, Ip MS. Obstructive sleep apnoea in Asia. Int J Tuberc Lung Dis. 2007; 11(1):2-11.

14. Young T, Evans L, Finn L, Palta M. Estimation of the clinically diagnosed proportion of sleep apnea syndrome in middle-aged men and women. Sleep. 1997; 20(9):705-6.

15. Netzer NC, Stoohs RA, Netzer CM, Clark K, Strohl KP. Using the Berlin Questionnaire to identify patients at risk for the sleep apnea syndrome. Ann Intern Med. 1999;131(7):485-91.
16. Chung F, Yegneswaran B, Liao P, et al. Validation of the Berlin questionnaire and American Society of Anesthesiologists checklist as screening tools for obstructive sleep apnea in surgical patients. Anesthesiology. 2008; 108(5):822-30.

17. Sharma SK, Vasudev C, Sinha S, Banga A, Pandey RM, Handa KK. Validation of the modified Berlin questionnaire to identify patients at risk for the obstructive sleep apnoea syndrome. Indian J Med Res. 2006; 124(3):281-90. 
Appendix A

Name:

\section{BERLIN QUESTIONNAIRE}

Height (m)

Weight $(\mathrm{kg})$

Age

Male/Female

Please choose the correct response to each question.

\section{CATEGORY 1}

\section{Do you snore?}
a. Yes
b. No
c. Don't know

If you snore, please answer questions 2-5 in this category. If not or you don't know, proceed to question 5.

\section{Your snoring is:}
a. Slightly louder than breathing
b. As loud as talking
c. Louder than talking
d. Very loud - can be heard in adjacent rooms

3. How often do you snore?
a. Nearly every day
b. 3-4 times a week
c. 1-2 times a week
d. 1-2 times a month
e. Never or nearly never

4. Has your snoring ever bothered other people?
a. Yes
b. No
c. Don't know

5. Has anyone noticed that you quit breathing during your sleep?
a. Nearly every day
b. 3-4 times a week
c. 1-2 times a week
d. 1-2 times a month
e. Never or nearly never

\section{CATEGORY 2}

6. How often do you feel tired or fatigued after your sleep?
a. Nearly every day
b. 3-4 times a week
c. 1-2 times a week
d. 1-2 times a month
e. Never or nearly never

7. During your waking time, do you feel tired, fatigued or not up to par?
a. Nearly every day
b. 3-4 times a week
c. 1-2 times a week
d. 1-2 times a month
e. Never or nearly never

8. Have you ever nodded off or fallen asleep while driving a vehicle, while waiting for appointment with the doctor, while watching television at home, or while waiting in line to make payment for a telephone bill or electricity bill?
a. Yes
b. No

If yes, answer the next question. If not, go straight to question 10.

9. How often does this occur?
a. Nearly every day
b. 3-4 times a week
c. 1-2 times a week
d. 1-2 times a month
e. Never or nearly never

\section{CATEGORY 3}

10. Do you have high blood pressure?
a. Yes
b. No
c. Don't know 
Name:

\section{BERLIN QUESTIONNAIRE}

Taas $(\mathrm{m})$

Bigat $(\mathrm{kg})$

Edad Lalaki/Babae

\section{PANGKAT 1}

7. Sa oras na ikaw ay gising, nakaramdam ka ba ng pagod?

\section{Humihilik ka ba?}
a. Oo
b. Hindi
c. Di ko alam

Kung humihilik ka, sagutan ang tanong 2-5 sa pangkat na ito. Kung hindi o hindi mo alam, pumunta sa tanong 5.

\section{Ang iyong paghilik ay:}
a. Mas malakas sa paghinga
b. Kasing lakas ng pagsasalita
c. Mas malakas sa pagsasalita
d. Napakalakas - maririnig sa kalapit silid

3. Gaano kadalasa kang humilik?
a. Halos araw-araw
b. 3-4 beses sa bawat linggo
c. 1-2 beses sa bawat lingo
d. 1-2 beses sa bawat buwan
e. Hindi kahit kalian o halos hindi

4. Ang hilik mo ba ay nakakabagabag sa iba?
a. Oo
b. Hindi
c. Di ko alam

5. May nakapansin bang tumigil ka na sa paghinga sa pagtulog?
a. Halos araw-araw
b. 3-4 beses sa bawat linggo
c. 1-2 beses sa bawat lingo
d. 1-2 beses sa bawat buwan
e. Hindi kahit kalian o halos hindi

\section{PANGKAT 2}

6. Gaano kadalas kang makaramdam ng pagod tapos matulog?
a. Halos araw-araw
b. 3-4 beses sa bawat linggo
c. 1-2 beses sa bawat lingo
d. 1-2 beses sa bawat buwan
e. Hindi kahit kalian o halos hindi

8. Naidlip ka na ba o nakatulog habang nagmamaneho ng sasakyan, habang naghinintay sa doktor, habang nanonood ng telebisyon sa bahay o habang nakapila sa pagbayad ng kuryente o telepono?
a. Oo
b. Hindi

Kung oo, sagutan ang tanong 9. Kung hindi, pumunta sa tanong 10.

\section{Gaano kadalas ito mangyari?}
a. Halos araw-araw
b. 3-4 beses sa bawat linggo
c. 1-2 beses sa bawat lingo
d. 1-2 beses sa bawat buwan
e. Hindi kahit kalian o halos hindi

\section{PANGKAT 3}

10. Meron ka bang alta presyon?
a. Oo
b. Hindi
c. Di ko alam

a. Halos araw-araw

b. 3-4 beses sa bawat linggo

c. 1-2 beses sa bawat lingo

d. 1-2 beses sa bawat buwan

e. Hindi kahit kalian o halos hindi 